\title{
Emociones y sentimientos patrióticos (1767-1828): Esbozo para un estudio de los patriotismos en el Río de la Plata
}

\author{
Emotions and patriotic feelings (1767-1828): Outline for a study of patriotisms in the Río de la Plata
}

Jaime Peire

DOI: https://doi.org/10.24215/2314257Xe107

CONICET/ Universidad Nacional de Tres de Febrero,

Argentina

jpeire@untref.edu.ar

Recepción: 11 Diciembre 2019

Aprobación: 20 Febrero 2020

\section{Resumen:}

El objetivo de este artículo, parte de un trabajo más amplio ya en curso, es trazar el esbozo de un estudio en torno a las emociones y sentimientos patrióticos durante el ciclo revolucionario. Para ello, es preciso detectar y analizar las distintas patrias que circulaban en el período: estudiándolas, se pueden comprender mejor esos sentimientos porque ellos las construían y las patrias subsistían en ellos. Utilizaré el corpus lírico y dramático culto y de corte popular, y otras fuentes seleccionadas para el caso, atendiendo al zócalo del discurso, al modo de enunciación y a su tono, y ponderando la responsividad del discurso (Arfuch, 2002). También se analizan los aspectos y categorías fundamentales a tener en cuenta a la hora de estudiar emociones y sentimientos patrióticos, motores y guías de los patriotismos del período.

Palabras clave: Emociones y sentimientos patrióticos, Río de la Plata-1767-1828, Sentimientos de pertenencia, Patria/s, Patriotismos.

\section{Abstract:}

This article, which is part of a broader research, intends to study the patriotic emotions and feelings during the revolutionary cycle by detecting and analyzing the different notions of homeland that coexisted throughout the period. By approaching those notions, it is possible to grasp the feelings and emotions they encompassed as well as to ponder the extent to which they were the driving forces of patriotism. The research relies on a corpus of lyric and dramatic texts both cult and so-called "popular". The analysis focuses on the plinth of the speech, the kind and tone of the enunciation, and the responsivity of the discourse (Arfuch, 2002).

KEYWORDS: Emotions and patriotic feelings, Río de la Plata 1767-1828, Sense of belonging, Homeland/s, Patriotism/s.

\section{INTRODUCCIÓN}

El período que aquí se pretende analizar -desde la expulsión de los jesuitas hasta el advenimiento del gobierno de Juan Manuel de Rosas en Buenos Aires- se inserta en una serie de grandes cambios a nivel local, regional y mundial. América hispánica en general y el Río de la Plata en particular no fueron la excepción. Estas mutaciones alcanzaron a todas las esferas de la vida individual y colectiva y desembocaron en el caso de Hispanoamérica en la separación definitiva del Imperio hispánico y el advenimiento de nuevas -modernasrepúblicas. Ellas ocuparon su lugar -más tarde o más temprano- como entes políticos con una legitimidad que tardaría bastante en consolidarse (Annino, Castro, Guerra, y Leiva, 1994).

En el caso del Río de la Plata -como en los demás espacios políticos- "la Nación" (o el Estado-Nación, si se prefiere) concentró las miradas y podría decirse que fue la gran protagonista de la historiografía hasta la llegada de otra mirada radicalmente diferente, que consideraba que la economía era lo que debía ordenar el relato histórico de la causación (Halperín Donghi, 2001, pp. 20-21). Pero en los finales de los años ochenta surgió una nueva historia política que -aunque recogía algunos de los planteos de esta historia de tinte económicosocial- otorgó una autonomía, profundidad y potencia narrativa inusitada al análisis político (Guerra, 1989 y 2003). ${ }^{1}$ 
En paralelo con el cruce de estas miradas nos interesa destacar que surgió un debate acerca del concepto de Nación en clave histórica. Es decir, acerca de si había habido o no una tal en el Río de la Plata después de la revolución de Mayo o incluso desde antes, entendiendo por nación el contemporáneo Estado-Nación. El tema de la Nación o del concepto de Nación, si bien dejó abundantes frutos en algunos tópicos, obturó la profundización de otros. Por ejemplo, el de la patria, que se estudió por carriles paralelos o aleatorios hasta la aparición de la "historia popular" de la revolución de mayo, cuando comenzó a verse su importancia central. Todo esto de alguna manera desembocó en una autocomprensión más clara a la hora del balance y festejo de los bicentenarios (Nun, 2005; Peire, 2018).

Casi simultáneamente estalló, literalmente, en las Ciencias Sociales y en las Humanidades el Affective turn o "giro afectivo". Estos cambios no pasaron inadvertidos. Este abrupto giro enfocaba las cosas de un modo radicalmente diferente y tomaba distancia del Linguistic turn. La historiografía comenzó a preguntarse -aun antes de que estallase el Giro afectivo- si había vida fuera del Giro lingüístico y de la historia conceptual: si no sería importante interrogarse acerca de las emociones y sentimientos de las personas y de los grupos, que finalmente no siempre resuelven sus conflictos ni toman sus decisiones de manera plenamente coherente y racional.

El objetivo fundamental de este trabajo es trazar un esbozo de cómo realizar un estudio acerca de los sentimientos patrióticos que satisficieron la demanda de arraigo durante el ciclo revolucionario. Este estudio -sin estar terminado todavía- tiene un grado de avance suficiente como para ser presentado aquí. Por supuesto no es (ni pretende ser) necesariamente la única posibilidad de hacerlo; pero es un modo de estudiar los sentimientos de pertenencia que puede disparar otros estudios en esa dirección, dinamizando al mismo tiempo el campo de la historia de las emociones que el Affective turn ha potenciado.

Para ello es preciso atender, percibir y analizar las patrias distintas, dinámicas y cambiantes que circulaban en ese período, provenientes de diferentes sistemas simbólicos. En efecto: estudiándolas, se pueden comprender mejor esos sentimientos porque ellos surgieron en el contexto de los cambios que se fueron gestando y consolidando en ese período.

\section{UN ESTUDIO HISTORIOGRÁFICO DE LAS EMOCIONES Y LOS SENTIMIENTOS PATRIOS}

El estudio de los sentimientos sugiere que serían un elemento por el cual el hombre enfrenta los cambios que se van dando en su contexto natural y sociocultural y les va otorgando una respuesta adaptativa. Esa adaptación sería una constante evaluación, una interfaz permanente entre la mente y la sensibilidad. Esta interfaz permite tener cierto equilibrio emocional para tomar decisiones frente a esos cambios de manera inmediata porque afectan al sujeto que los vive, requieren a veces de respuestas instantáneas y, otras veces, generan una adaptación más estable.

Estas decisiones vienen de -por un lado- y van -por el otro- a circular en una segunda interfaz social y cultural que va modulando emociones y sentimientos. El contexto sociocultural sería el que estaría desencadenando la activación (o inhibición -con sus intermedios: estimulación, ralentización, acercamiento, evitamiento, etc.) de nuestras disposiciones emocionales, motivando la actuación u omisión concreta. Estas activaciones estarían en el nivel estímulo-respuesta, pero también de distintas evaluaciones cognitivas acerca de cómo el sujeto queda situado con respecto a los acontecimientos o cambios del mundo exterior que confluirían en una evaluación central. (Rime, 2005, pp. 67-84; Rodríguez Valls, 2015, pp. 72-75). De esta manera, responden a la demanda de sentido procedente del mundo de la vida y lo construyen al mismo tiempo (Arregui, 2003; Ciompi, 2012; Martínez, 2000; Rimé, 2005; Scheer, 2012).

En el período estudiado, desde la expulsión de los jesuitas hasta la llegada del gobierno de Juan Manuel de Rosas, se produjeron muchos cambios en el Río de la Plata y si se pretende estudiar las identidades -quizás mejor sería decir los procesos de identificación-, es necesario estudiar las distintas patrias que los mismos sentimientos fueron acuñando en ese mundo vital o de la vida (Monteagudo, 2001; Blumenberg, 2013): esas 
patrias evacuaban los procesos identitarios que se iban dando aunque, por supuesto, sin agotarlos. Pero no se pretende aquí estudiar las identidades per se (Descombes, 2013; Hall y De Guy, 2003). ${ }^{2}$ No iremos más allá de los sentimientos patrióticos y de las patrias. Sólo estudiaremos las identidades en cuanto los procesos de identificación están contenidos en las patrias. Nos interesan más las emociones y los sentimientos que las identidades en y por sí mismas.

¿Cómo estudiar algo tan sutil, pero al mismo tiempo omnipresente? Hay muchas opciones, me parece. La que aquí propongo no es la única. Sin embargo, creo que permite avanzar en los estudios de esos procesos de identificación que antes eran nombrados de manera institucional como "nación" "estado" "monarquía" o aun "república". Los redirecciona en otro ámbito historiográfico, que es la historia cultural y, dentro de ella (aunque esto es discutible pero esa discusión no lo daremos aquí), la historia de las emociones y de los sentimientos, mediante el estudio de las patrias.

¿Por qué esto es pertinente y, aún más, relevante? Desde que el estudio de la nación dejó de ser el deus ex machina de la historiografía argentina hace unos 30 años ese vacío nos dejó frente al tema de la patria. Este tema estaba ocluido por la hipertrofia de la nación. Esto está claro - por ejemplo- en el discurso nacionalista de Mitre, pero también en los discursos identitarios -válidos y legítimos- más recientes.

La Nación empujó la mirada hacia el borde de la patria. Pero al ser confrontada esta con el mundo empírico, con las fuentes, se observan iconografías, imágenes, metáforas, retóricas, sinécdoques, metonimias, hipérboles; lenguajes, en suma, que contienen sentidos y significados muy diversos. Estos sentidos y significados conviven al mismo tiempo que sienten y ven -perciben- distintas patrias y pugnan por instituirlas. Ellas no son "puras"; son una negociación permanente que produce híbridos, que es lo que generalmente encontramos en las fuentes del período. ${ }^{3}$

No se busca tanto explicar los "porqués" de esos sentimientos que construían esas patrias cuanto de entender los "cómo" se manifiestan con ocasión de las patrias que procuraban construir por medio de los patriotismos y sus procesos dinámicos de despliegue en el área rioplatense. Se incluyen algunos puntos colindantes, con los que ellas y ellos (las patrias y los patriotismos) interactuaron. Me refiero a casos específicos como la Banda Oriental, el Alto Perú y el Perú mismo. En algunos casos esas patrias rioplatenses no pueden entenderse con cierta profundidad sin mirar también distintas áreas en donde el conflicto las llevó a desarrollarse. No es algo arbitrario; las fuentes van señalando áreas donde estos sentimientos patrióticos van formando círculos concéntricos. Se operará con una mirada radial, conservando el centro de interés en Buenos Aires, pero no de modo exclusivo en esta área.

Estas distintas patrias y sus híbridos remiten a paradigmas culturales diversos: urdimbres de significados que dan cuenta de esos fenómenos de manera muy distinta (Peire, 2008). Si miramos el lapso señalado, puede decirse que hablamos entre dos paradigmas culturales principales, el Barroco y la Ilustración, y sus derivaciones híbridas. Se han utilizado muchas fuentes para estudiarlos en diversos períodos. Pero me parece adecuado estudiarlos desde el punto de vista de los sentimientos y su circulación y apropiaciones más que del pensamiento formulado en ideas "claras y distintas".

Tomamos la opción de estudiar las patrias y los afectos que las construyen como si aquello con lo que nos identificáramos no fuera lo que pensamos o lo que hacemos sino una tercera cosa. Como si nos identificáramos con lo que sentimos o deseamos. No voy a discutir ahora si lo que digita lo que pensamos son los sentimientos (o mejor, las pasiones en una semántica más antigua), como sugería tempranamente David Hume, pero parece evidente que los sentimientos son muy cercanos a los pensamientos y tienen una historia que contar, algo que decir. ${ }^{4} \mathrm{O}$ dicho de otra manera: ¿̨se puede, entender los cambios profundos del período que proponemos estudiar -y en realidad de cualquier período- sin tratar de comprender, o ignorando, los sentimientos y sus cambios? 


\section{ELUSIVIDADES DE LAS DEFINICIONES E IDEAS SOBRE LA PATRIA}

En el período que se ha demarcado es difícil no remitirse a la época colonial porque en su inicio el Río de la Plata formaba parte de la Monarquía hispánica y ese factor tiene una duración más larga que la periodización política fáctica. Es pertinente en este punto recoger una recomendación de uno de los autores que trata este tema en ese período:

La idea de patria esta siempre llena de problemas, se sustrae a toda definición formal, cambia de contenido con el mudar de las situaciones históricas, presenta significaciones diversas según los puntos de vista de las clases sociales, y nada hay más demagógico y simplista que atribuirle un contenido universal y permanente.

Este autor -sin llegar a definir la patria- asienta varias cuestiones que se relacionan con este trabajo: la idea de una patria va junto a la emoción que se siente por ella. La confrontación entre las diferentes patrias pasadas con la actual permite observar "que la idea de patria también tiene un desarrollo histórico, y que su trayectoria va desde una patria de pocos hacia una patria de todos” (Martínez Peláez, 1998, pp. 34-35 y 524).

Hay, pues, patrias -según el autor- y está también la trayectoria de una patria. La patria se comprende en la perspectiva de esa trayectoria. Pero cualquier definición de patria que pretenda darse en la Hispanoamérica de principios del siglo XIX no puede evitar mirar hacia la "madre patria": siempre la patria ha sido considerada como "madre".

Para Gil Pujol, patria era usado como el lugar del nacimiento (2004, pp. 39-40). Pero el vocablo tiene una trayectoria que el autor se esfuerza por seguir. "patria" también comportaba -en las Partidas- un compromiso (dulce est pro-patria mori). "Los artesanos y la gente común compartían estos sentimientos de compromiso antes que el mundo de la política municipal oficial, que a veces le resultaba distante.” (p. 42). Ya hacia el final del XVI y en el XVII un supuesto común en Europa -según este autor- era que "la unidad de creencias suponía el requisito principal para que una comunidad pudiera vivir en concordia”, cuestión importante en España con judíos y musulmanes (p. 43). Más adelante había una tensión por asignar la patria al lugar de nacimiento o al reino, que se resolvía en la patria -ya reino, ya lugar de nacimiento- "como un locus primario de lealtad frente a la Monarquía (p. 52). Con posterioridad -a partir del mito de la reconquista del reino visigótico-, los borbones intentaron construir una Monarquía española "de una sola naturaleza” de raíces castellanas (pp. 68-69).

Donezar Díez (2004) habla de la nación-patria. Define ante todo la patria como el lugar de trabajo de los habitantes de los oscuros años altomedievales: el pedazo de tierra que sembraban y cosechaban. "Entonces la patria era esa 'tierra querida' en la que habían nacido y que la trabajaban para obtener su sustento" (2004, p. 95). Más adelante, con la aparición de reinos y monarquías, cobró importancia el concepto de natural, cuyo conjunto conformaba una nación (con un territorio más grande que aquel en el que se había nacido, pero al que también se pertenecía). Con ambos se tenía un "complemento sentimental y afectivo". Pero mientras que "nación” se refería más bien -según el autor- a que garantizaba la "libertad y felicidad de los hijos (p. 102), "patria" implicaba un "apego material, más que espiritual, a la tierra por parte de los nacidos en ella y que podía llegar a incluir una especie de compromiso implícito de defenderla (p. 192). La Monarquía era precisamente- la unión entre esas naciones-patrias.

Para este autor, en el siglo XVIII el proyecto ilustrado sería el paso de las naciones-patrias a una naciónpatria homologada en un espacio físico y social. La invasión napoleónica habría significado que las juntas provinciales representaban las naciones-patrias fundidas inmediatamente en el gobierno de una sola nación que desemboca en la Junta Suprema Central: "no fue el 'soñado pensamiento de la unidad de España' sino la necesidad práctica de una conciencia nacional unitaria." Pero estaba claro que la invasión napoleónica era una invasión a la patria y sus defensores, los patriotas (pp. 109-113).

Javier Fernández Sebastián (2005) es quizás quien ha hecho uno de los estudios más amplios acerca del concepto de patria (junto con el de estado y nación) en el mundo iberoamericano. Patria tendrá un contenido 
territorial e institucional -en sus estudios lexicográficos-, junto con una "temperatura afectiva", como se observa en la manida metáfora de la patria como Madre (2005, pp. 161-162). En el siglo XVIII la semántica va asignando al término un concepto más “cívico y más nacional”: en los círculos ilustrados se tendía a ampliar el radio de lo que se consideraba patria, desde la patria chica hacia los reinos y hasta la misma Monarquía, enfatizando el lazo horizontal de ciudadanos más bien que el vertical de vasallos (p. 269).

El final del siglo desarrolló una semántica complementaria del vocablo. Por un lado, al igual que lo decía la Enciclopedia, patria contenía también el lugar donde nacíamos y que defendía las libertades y la felicidad de sus miembros. Por el otro, las Sociedades de amigos del país la nombraban con un sentido esencialmente socioeconómico, débilmente politizado. Este último sentido venía también asociado a una nueva sociabilidad (2005, p. 171).

El fin de siglo trajo de vuelta a los clásicos romanos (Cicerón, Tácito, Tito Livio) al contenido de lo que sería la patria, mixturando a veces el lenguaje "utilitario, iusnaturalista, escolástico, liberal, clásico, republicano" cargándolo de sentidos que lo hacen complejo al lector actual (pp. 172-173). La invasión napoleónica volvió a resemantizar el término -sin que perdiera todas estas connotaciones anteriores- con cuestiones de tradición y religión, y fortaleció su sentido de cuerpo social, con lo que "la patria entra en dosis generosas en la gran coctelera de discursos políticos que se difunden por toda España en esos años" (2005, p. 174).

Elliot (2004) ha intentado condensar el recorrido de la idea de patria en la entera Monarquía española como "una entidad constituida por el rey y el pueblo unidos con el rey como caput communitatis" estructurada según pactos $(2004$, p. 27). El Rey era natural de cada patria y la cabeza de todas; incluidas las americanas, cualquiera fuera su estatus jurídico (p. 28). ${ }^{6}$ La patria en América, señala Elliot, era "el orgullo del lugar -un lugar bendecido por Dios como ningún otro que iba a ser la piedra angular del edificio cada vez más complejo del patriotismo criollo" (p. 30). Tenemos aquí de vuelta la puesta en juego de las emociones y sentimientos en la definición de patria. Más tarde, los Borbones trataron de imponer una nación vertical donde los Austrias habían construido un delicado pero efectivo Imperio horizontal dentro de un imaginario pactista.

La patria criolla se desplegaba así como una porción particular de un Imperio universalista. Según el concepto del mismo discurso hispánico, esta patria era una organización natural indisponible, la república, vinculada por un pacto al resto de la Monarquía mediante su cabeza: el Rey (Agüero, 2013).

Precisamente, porque él era el caput communitatista de ese Imperio variopinto, la crisis de 1808 colocó a la patria criolla en una situación que la excedía al producirse la vacatio regis. El Rey mismo era la piedra angular del Imperio. En su ausencia había que moverse rápidamente para restaurar esa herida mortal para la existencia política según era entendida por el patriotismo criollo desde el siglo XVII y aún antes (cfr. Brading, 1998; Rodríguez García, 2003).

El patriotismo criollo había resistido el embate de las rebeliones indígenas. Ese proceso había tenido sus costos en el "delicado equilibrio entre Rey y patria." Ahora en cambio no resistió la nueva situación: en ausencia del Rey la patria se volvía el referente fundamental de la comunidad política y hacia ella se volvió la mirada (Elliot 2004, 34).

Dicho en palabras de Annino (2008), el patriotismo criollo había sido construido sobre bases escolásticas que neutralizaban la omnipotencia de la conquista del siglo XVI y autorizaban a los americanos a funcionar autónomamente como ciudadanos libres dentro de un imperio cristiano -o en el seno de un proceso de cristianización- con un referente universal trascendente. Pero la Ilustración europea socavó la legitimidad de esa explicación porque aspiraba a legitimar el orden político con un referente "totalmente mundano": tal es el proceso que Annino llama "el ocaso del patriotismo criollo". El lugar asignado a los criollos en ese nuevo orbe imaginario era el de seres inferiores, por habitar un lugar húmedo que los producía, como decían los corifeos de la Ilustración De Paw, Buffon y Raynal (Annino, 2008, pp. 13-27; Lavallé, 2010; Maggio Ramírez, 2016). Contra esa discriminación basada en supercherías de gabinete y observaciones de viajeros no calificados se alzaron las voces de los patriotas criollos, ahora con un patriotismo ilustrado. 
La patria criolla no era pertinente en el mundo ilustrado y Francisco Clavigero -en el caso mexicano, en otras partes de América hispánica hubo otros- fue el que lo liberó de su procedencia cultural barroca, de su lastre "de la condenación agustiniana y del triunfalismo joaquinita", como anota Annino (Annino, 2008, p. 18; Ternavasio, 2007, p. 35). ${ }^{7}$ En esa línea, Pilar González Bernaldo y Matías Maggio Ramírez -entre otroshan insistido en el contenido de la Patria como la inscripción en el proceso universal civilizatorio que vendría a ser la matriz de esa patria criolla, ahora ilustrada, que se desplegaría después (González Bernaldo, 2001; Maggio Ramírez, 2016).

Víctor Gayol, para México, y Gabriela Tío Vallejo, para el Río de la Plata estudiaron cómo los Borbones se esforzaron por desplazar del imaginario militar las preminencias de sangre y de nobleza para colocar la virtud como epicentro de la lealtad al monarca. Esto sentaría las bases para que en las invasiones inglesas los cuerpos de milicianos -ciudadanos en armas- cobraran importancia y se abriera un espacio de legitimidad de otro modo indisponible (González Bernaldo, 1990). Se intersectan aquí dos patriotismos: hacia el Imperio español y hacia la patria territorial de la ciudad. Más tarde habría una identificación entre la patria y el ejército revolucionario que sería decisiva y que, para Tío Vallejo, se habría originado en el sentimiento de orfandad durante las invasiones: mientras los militares/vecinos/patriotas habrían salvado a la patria, los gobiernos la habrían perdido (Tío Vallejo y Gayol, 2005).

En los últimos veinte años hubo un desplazamiento significativo en la perspectiva del estudio de la patria. $\mathrm{Al}$ enfocar la sociedad y la política -ya producido el boom de la historia política de los noventa-, varios historiadores variaron el punto de mira, de las élites hacia las capas más bajas de la sociedad, enfocando la historia "desde abajo" (Fradkin, 2008, pp. 9-26). Desde allí percibieron, aunque no fuera el objeto central de su estudio, cierta identificación con la patria que surgía en la revolución de la cual esas capas bajas eran -por lo menos- partícipes necesarios y de la que se sentían coprotagonistas en su construcción.

Di Meglio (2006) subraya que durante la movilización que duró desde 1806 hasta el advenimiento de Rosas la plebe -como eligió llamar a ese grupo, no de manera aleatoria- tuvo una participación destacada y los procesos políticos que se desarrollaron en ese período no pueden ser explicados cabalmente sin su estudio profundo. En ese estudio "se observa una fuerte identificación de la plebe con la patria" y concluye que "el elemento que estuvo en la base de la adhesión plebeya a la revolución por ella creada fue la identificación con la Patria” (Di Meglio, 2006, pp. 16 y 315).

En la época colonial la patria tenía un contenido religioso. A partir de las invasiones inglesas, y después mucho más con la revolución de mayo la patria se convirtió en una deidad laica y el Rey fue haciéndose menos visible en la tríada Patria-Dios-Rey. La patria fue el concepto político central en el período que analiza Di Meglio: "la patria quedó como el principio aglutinador, con fuertes contenidos emotivos y afectivos en su invocación” (p. 120).

Hemos visto así -en apretada síntesis- un recorrido de las ideas de patria y su uso en la historiografía, que en muchos momentos subraya una carga emotiva, pero sin estudiar de manera sistemática ese movimiento afectivo que impulsaba a la acción, y cómo era esa carga emocional concreta.

\section{Emociones, SENTIMIENTOS, DESEOS, AFECTOS, PASIONES}

Hasta hace poco tiempo la historiografía utilizaba la expresión "historia de las sensibilidades" con la que se aludía a la percepción sensitiva. Pero, como es sabido, el Giro afectivo colocó a la emoción (y demás expresiones correlativas) en primer plano y desplazó la sensibilidad a un segundo. De hecho, si uno mira el índice del muy recomendable Historiographies (obra que pretende sintetizar los principales debates contemporáneos y que citamos en este breve artículo más adelante), la historia de la sensibilidad aparece: pero no así la de las emociones, sentimientos, etc. Tampoco el Diccionario de Ciencias Históricas menciona los temas aludidos, aunque le dedica una entrada al tema del cuerpo, que es uno de los accesos al Affective turn (Burguière, 2005, pp. 162-166). Al parecer, no estaba en el radar temático de los autores de estas obras una 
historia de las emociones autónoma, que venía deslizándose por otros carriles o que, en todo caso, todavía no había estallado en Francia (Mazurel, 2010).

Intentar una definición cerrada sobre cada uno de los términos que se usan para designar los afectos y emociones en el Giro afectivo es complejo. ${ }^{8}$ Más aún en un marco historiográfico que pretende historizar las emociones. Implicaría ingresar en una discusión teórica que suele terminar en el enrolamiento -muchas veces aporético- en algunos de los diversos enfoques teóricos que los debates en torno a las emociones han suscitado: básicamente, el de si hay una brecha entre la emoción, su toma de conciencia y su expresión. ${ }^{9}$

El problema de la terminología que habría que usar para designar afectos, emociones, sentimientos, etc., se conecta con el problema de si las emociones son prelingüísticas. Esto está íntimamente relacionado a si son representacionales y entran en el mundo del significado (o no); tanto como a si se refieren en primer lugar más al cuerpo que las contiene y en una segunda instancia a la mente, algo que nos remitiría a un presunto dualismo cartesiano. ${ }^{10}$ Estos nudos de problemas remiten además a otros acerca de si las emociones son universales o más bien construcciones socioculturales particulares que varían según la cultura o el contexto histórico. La biología contra lo específicamente humano, la naturaleza contra la cultura, lo particular y lo universal, cuerpo contra mente, cognición contra emoción y otras (supuestas) oposiciones.

Hoy más bien se tiende a pensar en realidades híbridas y complejas en el caso del ser humano, aunque se dé prioridad al contexto cultural e histórico. Hay autores que piensan que ese contexto cultural y temporal puede modificar y de hecho modifica la configuración neuronal del sujeto: eso entraría dentro del campo de la neurohistoria (Boddice, 2018, pp. 155-167; Martínez Freire, 2000). Esto abre un campo de investigación sumamente interesante y que puede poner en contacto estudios de las ciencias duras hermanados con otros de las ciencias humanas y sociales.

Si se supone, por ejemplo -como lo hacen otros estudios- una unión y funcionamiento indivisible entre "el cuerpo" y "la mente" (Lays, 2011, pp. 450-456), se reservaría para emoción el primer impacto -más fugaz e intenso- de algo que afecta al sujeto: algo lo toca, lo golpea y eso produce un efecto instantáneo en el cuerpo. En cambio, se reserva para sentimiento la asunción más estable de la experiencia del sujeto de eso que ha tocado a la persona. Afecto, en cambio, nombraría algo genérico que los englobaría, de menor definición y que aludiría o involucraría una faceta más relacional. ${ }^{11}$ Pasión, por otro lado, habla de algo que arrebata y ante lo cual no se tiene mucha opción. El sujeto es más bien pasivo ante un vendaval que lo arrastra; ambas palabras, "pasión” y "pasivo” tienen una misma raíz, del griego paschêin (Eustace, 2012).

Lo que está claro hasta ahora es que, en general, en la órbita que gira en torno al castellano "Historia de las emociones" es la expresión más adoptada. En este caso se usará mayormente el vocablo "sentimientos", porque se apunta más a hábitos estables, a prácticas culturales y sobre todo a estándares de inteligibilidad (y de inteligibilidad afectiva) del mundo "real". Se aludirá a "emociones" cuando se refiera más bien al esquema estímulo-evaluación corporal-respuesta: algo más espontáneo. En cambio, "sentimiento" sería la asunción más bien consciente del sujeto en su experiencia de esa emoción y su despliegue más extendido en el tiempo, en general como hábito estable o práctica sentimental. El sentimiento sería así más libre en cuanto deja un espacio a la aceptación o rechazo de la emoción que asume, aunque la parte corporal, alguna parte corporal, sería imprescindible también para que haya sentimiento. El tiempo de duración de ese estado afectivo podríamos llamarlo "estado de ánimo" o "humor". Siempre se está con algún estado de ánimo o humor; es algo que hay que tener en cuenta al estudiar la comprensión de las personas de los acontecimientos y entender sus acciones/reacciones. ${ }^{12}$

Pero, como se verá, a veces las fuentes apuntan a la pasión, por la que se entiende un ser afectados de una manera que no se puede controlar pero sin entrar en la polémica plurisecular de si las pasiones deben o no (o hasta qué punto) dirigir el comportamiento o las instituciones, etc.: justamente, en el período que estudiamos se estaba dirimiendo esa cuestión y cada bando adjudicaba al otro pasiones inconfesables mientras reivindicaba para sí pasiones "buenas"; al tiempo que otros directamente las condenaban in toto. ${ }^{13} \mathrm{El}$ uso del 
vocablo "pasión" cuando está tomado en forma positiva en las fuentes documentales -y tal el caso de la patriase acercaría más bien al sentido romántico. ${ }^{14}$

\section{Perspectivas metodológicas}

El objetivo, entonces, es profundizar y problematizar cómo una patria -las patrias- era percibida -eran percibidas-, de qué manera era/n sentidas: cómo y cuáles fueron los sentimientos que las construyeron. Por un lado, cuál era su naturaleza; por otro, cómo se expresaban y desarrollaban estos sentimientos y emociones en una performance patriótica en orden a construir esa/s patria/s. ${ }^{15} \mathrm{Si}$ atendemos al período, ella/s era/n o bien sólo un horizonte a alcanzar o bien no estaba totalmente coagulada su institución imaginaria. ${ }^{16}$

La pregunta sería, entonces, qué corpus documental podría responder o comenzar a responder la pregunta por los sentimientos que instituyeron (o habrían de instituir) esas distintas patrias sentidas, los que las soñaron, las señalaron y las nombraron. (Reddy, 2009; Frevert, 2011; Deluermoz, Fureix, Mazurel y Qualdi, 2012; Lloyd y Semo, 2014; Matt y Stearns 2014; Plamper, 2014 y 2015; Moscoso, 2015). En primer lugar, un estudio atento a la lírica y la dramática culta y "popular" -en general escrita por letrados- del período, que es lo que fundamentalmente trataremos de desarrollar aquí. ${ }^{17}$

Este corpus será contextualizado por otro que está conformado por la prensa del período. A esto se le sumará un amplio abanico de fuentes que van desde correspondencia personal o secreta, diarios personales, diarios de guerra, diarios de viaje de viajeros locales o regionales, proclamas, discursos, sermones, oraciones fúnebres, arengas, panegíricos, memoriales, conferencias, distintos elementos normativos, bibliotecas, hasta llegar a las fuentes judiciales, que formarían como arbotantes del corpus central. Analizaremos sincrónica y diacrónicamente su semántica, estableciendo y comparando las trayectorias de las palabras y tratando por este medio de "comprender" su mapa semántico, los espacios sentimentales que establecen, y las prácticas sentimentales a las que remiten, para parafrasear a Monique Scheer (2012). Esto puede parecer un poco teórico, pero cuando se atiende al protocolo propedéutico que se ha operado no lo es tanto. ${ }^{18}$

Se trata de mirar el léxico de los afectos hacia las patrias que aparecen en las fuentes y atender a las repeticiones, los desplazamientos, los cambios, y finalmente los lugares -observando los deícticos, por ejemplo- desde donde son enunciadas, aunque esa enunciación no fuera explícita. Juntamente con ello, el tono de la enunciación, entendiendo por tono la forma de enunciar. ${ }^{19}$ Eso podría generar una empatía: pero una empatía que no es sólo eso; ella es confirmada o invalidada (o cambiada simplemente) por el ejercicio de la repetición.

Un buen ejemplo de esto es la idea o, si se quiere, el concepto de patria. Una semántica histórica fina conduce a una noción diferente de las que usualmente estamos acostumbrados a ver: el lugar de nuestros padres u otras nociones. Esto dicho más allá de la definición de patria -siempre un poco estática- de los diccionarios de la época, que reifican un concepto que en realidad estaba vivo. Ella era blandida por los actores sociales de las fuentes -en cambio- como un lugar que se estaba construyendo con determinadas particularidades según la patria proyectada o pergeñada desde el propio sentimiento más bien que sufriendo el fenómeno inverso: un lugar reflejado desde un contexto pero que refleja su propia mirada como sujeto (individual y colectivo) según el ángulo de la realidad -entre comillas- en que se encuentra.

"Lugar" es una palabra por demás importante cuando se habla del mundo de la vida y de procesos de identificación. ${ }^{20}$ En este lugar la persona se imaginaba a sí misma como conviviendo en sociedad placenteramente con su familia, amigos, conocidos y con el resto de la sociedad que la interpelaba vitalmente y en cuya construcción se involucraba, porque se reconocía dentro de cierta singularidad (cfr. Viroli, 1997, p. 77). No estoy hablando de una patria que ya ha colonizado y canonizado un ámbito geográfico particular todavía: el lugar es sobre todo social, cultural y sentimental también. ${ }^{21}$ Esta Patria a veces no existía cabalmente sino en esperanza. ${ }^{22}$ 
Tener como corpus central del estudio la lírica y dramática no significa volcar a la realidad histórica lo que dicen los personajes en esas obras sino ponderarlo según la responsividad del discurso para señalar la captura, la percepción, de una realidad que delinea un círculo o contorno identitario -o varios- en esas obras y al mismo tiempo muestra verosímilmente haber sido capturada por el discurso supuestamente ficticio. ${ }^{23}$ Es decir, se trata de buscar en el zócalo de ese discurso prácticas sentimentales de pertenencia verosímiles o inteligibles para un determinado estándar de inteligibilidad. Esto es, actor, sujeto, espacio y tiempo, para decirlo según especifica Jean Jacques Wunenburger acerca del imaginario del momento histórico al que remiten (Wunenburger, 2008; Eustace, 2012).

Un ejemplo de la verosimilitud que podemos encontrar en la lírica y la dramática (y, por tanto, del encuentro entre estos niveles de inteligibilidad) se encuentra en la pieza de Ambrosio Morante (1926) Defensa y triunfo del Tucumán, de 1821, compuesta como elegía a la muerte de Manuel Belgrano. El autor pone en boca de Belgrano la respuesta a la intimación realista antes de la batalla:

Que si osado / con la desventaja nuestra / sus proyectos temerarios / pretende formalizar, / se prepare al resultado/ de los funestos consiguientes / por la infracción al sagrado / derecho que las naciones / menos cultas, venerando / están en todos los pueblos. (...) / Sus flameantes estallos / serán el terrible impulso / para que mis esforzados / campeones hagan cenizas / a los siervos de Fernando. / Y entonces serán sus ruinas / el más indeleble fasto / que de nuestra libertad / el estandarte elevando / patentizen [sic] la energía / del miserable puñado / que se llamarán / sepulcros de los Tiranos. (Morante, 1926, pp. 119-120).

Al parecer, sin embargo, esa respuesta fue dada por Eustaquio Díaz Vélez a Pío Tristán en una carta que reza:

(...) y sólo serán sus ruinas el cuadro en que se eleve el estandarte de nuestra libertad: puede V.S. incendiar como promete las casas del Pueblo; pero esta infracción de los más sagrados derechos de los Pueblos le será a V.S. eternamente sensible sin respeto a todos los que hasta aquí han venerado las naciones menos cultas. ${ }^{24}$

Como se puede ver, ambas citas son muy parecidas -sospechosamente parecidas- pero dejan ver dos niveles para el lector avezado. En la versión de Morante de 1821 hay dos términos muy negativos adjudicados enérgicamente a Fernando VII (lo que ya es un anacronismo en sí mismo: se supone que los dos combatían por Fernando). En primer lugar, los soldados son, según Morante, “siervos de Fernando", algo que Belgrano -o Díaz Vélez, su lugarteniente- no hubiera escrito, por una norma de evidente prudencia. En segundo, que el puñado de "Valientes" tucumanos conducidos por un porteño, algo que se hace explícito varias veces en un momento de "anarquía", hará pedazos a esos siervos de los Tiranos: lo que equivale a decir que Fernando es un tirano; otro término anacrónico que no está en la breve carta de Díaz Vélez.

Podríamos decir que la operación historiográfica involucra tres estándares de inteligibilidad. En primer lugar, el de los "hechos mismos" (la batalla de Tucumán). Ellos interpelan a un segundo nivel hipotético de inteligibilidad, que sería el que las fuentes nos brindan (la composición lírica y la carta de Vélez a Tristán). El tercer nivel sería el de la inteligibilidad del mundo vital del historiador. Sin forzar demasiado las cosas, creo que se podría pensar un cuarto nivel de inteligibilidad, que sería el que el historiador construye por sí mismo en la compulsa de las fuentes propia e íntima que es su tarea.

Este hipotético nivel nunca resulta totalmente autónomo del tercer nivel (ninguno lo es en realidad) pero es relevante: significa el esfuerzo del profesional que intenta -es todo lo que se puede hacer, intentarlo- tomar distancia de las fuentes y constituir una imposible neutralidad; aunque" imposible" no implica que no haya grados y que no se consiga ningún resultado (todo esto sin destruir la pasión que todo objeto de estudio exige).

Una palabra sobre la densidad o peso específico de las "voces" es necesaria. No pretendo perimetrar las voces que se muestran en estas obras literarias. Me basta con mostrar las patrias que contienen, aun implícitamente. Sólo digo eso: son voces que señalan, describen, aluden o suponen círculos identitarios y manifiestan sentimientos que más tarde o más temprano interpelarán a la dinámica política del período de la cual no nos ocuparemos específicamente. 
Nos parece suficiente - por ahora- remitirnos al(os) grupo(s) coral(es) que elaboró(aron) las composiciones líricas y dramáticas. No se trata tanto de delimitar esa voz en "grupos articulados" cuanto de mostrar un contenido sentimental que va más allá de él. Algo que Susan Matt y Peter Stearns convalidan remitiendo precisamente a esa inteligibilidad que habilita la posibilidad del sentir en un grupo más amplio que el específico al que se pertenece. Esto tiene más pertinencia, sobre todo cuando hay de por medio publicaciones o impresos que hacen circular textos que contienen emociones, las despiertan, las estimulan, las desarrollan y las declinan en una apropiación o apropiaciones (cfr. Matt \& Stearns, 2014, p. 6).

Aquí se articularía la definición de patria que hemos brindado antes -algo vívido que es sentido muchas veces como una pasión- con el grupo emocional en el que la patria subsiste y es gestionada. Este no es ni el sujeto a un régimen emocional (Reddy) -algo demasiado estructurado para el caso- ni una comunidad emocional de carácter neto, cerrado (una totalidad ya nítidamente definida) (Plamper, 2014, p. 23).

En nuestro caso -siguiendo a Matt y Stearns-, los "patriotas" serían grupos (pues hay diferentes patrias emocionales que conviven) que se identifican con los textos que leen o escuchan leer y se emocionan y militan de alguna manera en la construcción de la patria en constante transformación.

Esto, aun considerando que la coralidad grupal y la recepción fueran originadas y traccionadas por individuos; pero individuos cuyas emociones partían de un mundo emocional íntimo (que in se no conocemos) y se proyectaban en un contexto relacional (Delgado, Fernández y Labanyi, 2018, pp. 15-18; Donati, 1997; Imízcoz, 2017, p. 22).

\section{CONCLUSIÓN: PERSPECTIVAS Y QUÉ SE ESPERA ENCONTRAR Y EXPLICAR}

Apenas hemos esbozado aquí lo que en parte ya se ha encontrado y se espera encontrar. Es decir, el cómo fue sentida, fueron sentidas, las patrias; con qué sentimientos y, sobre todo, qué contenido sentimental tenían esas patrias que estos sentimientos configuraban; y, por lo tanto -según se ha dicho-, qué características fundamentales tenían esas patrias que subsistían en esos sentimientos que eran relacionales de manera inmanente.

Se trata de explicar qué mirada había sobre esa patria propia, en muchos casos a construir (en otros casos ya construida y a conservar porque, por ejemplo, los realistas también tenían patrias, que se estudiarán). El contenido de los sentimientos patrióticos que convivían (que a veces formaban patrias contrarias pero no siempre contradictorias o en conflicto) y cómo fueron evolucionando y entrelazándose en una trama de significado sociocultural que las contenía, siempre teniendo en cuenta el área bonaerense y el Río de la Plata, y aquellos interlocutores de sus transformaciones en forma radial.

Diacrónicamente, aspiramos a que se entienda mejor también la dinámica sentimental del proceso revolucionario: cómo los distintos patriotismos fueron evolucionando y el potencial que tenían en su despliegue y en su relación con la dinámica política del período según lo que Ciompi (2001) afirma en su quinta propuesta: "los afectos son los motores y los organizadores esenciales de toda la dinámica psíquica y social". ${ }^{25}$ Así, para poner un ejemplo, desde el punto de vista emocional y sentimental las invasiones inglesas habrían sido más importantes que la Revolución de Mayo misma y la hicieron posible, desde luego, junto con sus consecuencias posteriores.

Es claro que esta operación historiográfica que aquí se pretende realizar no agota ni mucho menos el tema: es sólo una pista, un inicio si se quiere. Nada en la historiografía está clausurado ni es clausurable. Pero quizás es un estudio que permitiría un conocimiento más profundo de las emociones y los sentimientos que actuaban en el mundo vital, en los mundos vitales, que no sólo estaban en los discursos sino que, dado determinado contexto revulsivo, movilizó gente de muchos sectores, desde las élites hasta las clases populares, y vuelta hasta que el lazo bonaerense, que es el área que principalmente se pretende estudiar, se desprendió de la Monarquía policéntrica y clausuró su pertenencia política a ese conjunto porque se había constituido ella misma en el referente de su propio autogobierno. 


\section{Fuentes ÉDitas}

Acuña de Figueroa, F. (1978). Diario histórico del sitio de Montevideo en los años 1812-1814. Montevideo: Biblioteca Artigas.

Cancionero de las Invasiones inglesas (2010). Buenos Aires: Docencia.

Colección de Poesias Patrióticas (inédito de 1826). Buenos Aires: Docencia.

ElParnaso Orientalo Guirnalda poética de la República uruguaya (1837). Montevideo: Imprenta Oriental. Hidalgo, Bartolomé (1986). Obras completas. Montevideo: Biblioteca Artigas.

La Lira argentina o colección de piezas poéticas dadas a luz en Buenos Aires durante la guerra de su independencia [1824]. (1982). Buenos Aires: Academia Argentina de Letras.

López y Planes, V. (1808) El triunfo argentino. Poema heroico en memoria de la gloriosa defensa de la capital de Buenos-Ayres contra el ejército de 12.000 hombres, que la atacaron los días 2 a 6 de Julio de 1807. Buenos Aires: Imprenta de los niños expósitos.

Morante, A. (1926 [1821]. Defensa y triunfo del Tucumán. Pieza militar en dos actos. Buenos Aires: Instituto de Literatura Argentina, T IV, N³, 80-127.

Puig, J. C. (1910). Antología de Poetas argentinos. T I-IV. Buenos Aires: Martín Biedma e hijos.

Poesías desconocidas de la Independencia argentina (2018). Buenos Aires: Docencia.

Zeballos, E.S. (2018). Cancionero popular. Buenos Aires, Docencia.

\section{Periódicos}

“Reflexiones sobre el patriotismo". El Censor, 4 de febrero de 1812.

Gaceta de Montevideo, 1810-1811.

\section{ArCHIVOS}

Biblioteca Nacional de España (BNE)

Archivo General de Indias (AGI)

\section{FUENTES INÉDITAS}

Relación exacta de lo que ha sucedido en la expedición a Buenos Ayres que escribe un sargento de la comitiva de ese año de 1778 en las siguientes Décimas. BNE, Ms 10.942. f. 160 vta. y ss.

Quimper, M. Laicas vivacidades de Quimper, Antorcha Peruana: Acaecimientos del Peru en civiles guerras, promovidas por el Reyno de Buenos- Ayres, desde el año de 1809 hasta el de 1818. BNE, Ms 3.722.

Eustaquio Díaz Vélez a Pío Tristán. AGI, Tucumán, 24 de septiembre de 1812, Diversos 2-2-1-2.

\section{ReFERENCIAS}

Acuña de Figueroa, F. (1978). Diario histórico del sitio de Montevideo en los años 1812-1814. Montevideo: Biblioteca Artigas.

Agostini, H. N. (2000). Noticias históricas sobre las publicaciones periódicas en Buenos Aires, desde la época virreinal hasta la capitalización de la ciudad. En UNTREF, UNLAM, UNESCO, Ministerio de Cultura y Educación de la Nación. Transformaciones politicas, Sociales y Culturales en América latina a fin del milenio: los desafíos de la integración (pp. 377-415). Buenos Aires: Untref-UnLaM.

Agulhon, M. (1993). Nation, patrie, patriotisme en France du Moyen Age à nos jours. París: Documentation française. 
Jaime Peire. Emociones y Sentimientos Patrióticos (1767-1828): Esbozo Para un estudio de los Pat...

Annino, A. y Rojas, R. (2008). La independencia. Los libros de la patria. México: Fondo de Cultura Económica.

Annino, A., Castro Leiva, L. y Guerra, F. X. (1994). De los imperios a las naciones. Zaragoza: Ibercaja.

Agüero, A. (2013). Ciudad y poder político en el Antiguo Régimen. La tradición castellana. En V. Anzoátegui y A. Agüero (coords.). El derecho local en la periferia de la Monarquía hispana: Río de la Plata, Tucumán y Cuyo (pp. 121-184). Buenos Aires: Instituto de Investigaciones de Historia del Derecho.

Arfuch, L. (2002). Dialogismo. En C. Altamirano (Dir.), Términos críticos de sociología de la cultura (pp. 64-68). Buenos Aires: Paidós.

Arregui, V. (2003). La configuración cultural de la afectividad. En J. Choza (Ed.) Sentimientos y comportamiento (pp. 41-75). Murcia: Universidad Católica de San Antonio.

Boddice, R. (2018). The history of emotions. Manchester: Manchester University Press.

Blumenberg, H. (2013). Teoría el mundo de la vida. Buenos Aires: Fondo de Cultura Económica.

Brading, D. (1998). Orbe indiano. De la Monarquía católica a la república criolla, 1492-1867. México: Fondo de Cultura Económica.

Brunner, O., Conze, W. \& Koselleck, R. (Eds). (1972-1997). Geschichtliche Grundbegriffe: Historisches Lexikon zur politisch-sozialen Sprache in Deutschland (Vols. 1-9). Stuttgart: Klett-Cotta.

Burguière, A. (2005). Diccionario Akal de Ciencias históricas. Madrid: Akal.

Burke, P. (2010). Hibridismo cultural. Madrid: Akal.

Castoriadis, C. (1983). La institución imaginaria de la sociedad. Barcelona: Tusquets.

Ciompi, L. (2012). Emotions, Affects et logique affective. Leur place dans notre comprébension d'autre, et du monde. Recuperado de http://www.ciompi.com/pdf/Ciompi-Emotions-affects-et-logique-affective

Choza, J. (1983). Cambio sociocultural y acción política en el problema de los regionalismos. Revista de estudios politicos, 38, 147-168.

Dale Lloyd, J. y Semo, I. (2014) Memoria latente e historia de las emociones. Historia y grafia, 42, 9-14.

Delgado, L. E., Fernández, P. y Labanyi, J. (2018). La cultura de las emociones y las emociones en la cultura española contemporánea (siglos XVIII-XXI). Madrid: Cátedra.

Deluermoz, Q., Fureix, E., Mazurel, H. y Oualdi, M. (2012). Écrire l'histoire des émotions?: de l'objet à la catégorie d'analyse». Revue d'histoire du XIXe. Siècle. Société de la révolution de 1848 et des révolutions du XIXe. Siècle, 44, 155-189. https://doi.org/10.4000/rh19.4573

Descombes, V. (2013). Les embarras de l'identité. París: Gallimard.

Di Meglio, G. (2006). ;Viva el bajo pueblo! La plebe urbana de Buenos Aires y la politica entre la Revolución de Mayo y el rosismo. Buenos Aires: Prometeo.

Di Meglio, G. (2007). Patria. En N. Goldman (Ed.). Lenguaje y revolución. Conceptos políticos clave en el Río de la Plata, 1780-1850 (pp. 115-130). Buenos Aires: Prometeo.

Donati, P. (1997). Cambio social y pensamiento sociológico: hacia una teoría relacional. En V. Vázquez de Prada, I. Olábarri y F. Caspistegui, Para comprender el cambio social. Enfoques teóricos y perspectivas historiográficas (pp. 51-91). Pamplona: Eunsa.

Donézar Díez de Ulzurrun, J. M. (2004). De las “naciones-patrias” a la "nación-patria”. En A. Alvarez-Ossorio Alvariño y B. J. García. La Monarquía de las naciones. Patria, nación y naturaleza en la Monarquía de España (pp. 93-118). Madrid: Fundación Carlos de Amberes.

Eustace, N. (2012). 1812. War and the passions of patriotism. Philadelphia: University of Pensilvania Press.

Elliot, H. (2004). Rey y Patria en el Mundo hispánico. En V. Mínguez y M.l Chust. El imperio sublevado, Monarquia y naciones en España e Hispanoamérica (pp. 17-35). Madrid: CSIC.

Enciso Domínguez, G. y Lara, A. (2014). Emociones y ciencias sociales en el s. XX: La precuela del giro afectivo. Athenea Digital, 14(1), 263-288. Recuperado de http://dx.doi.org/10.5565/rev/athenead/v14n1.1094.

Fernández Sebastián, J. (2005). Estado, nación y patria en el lenguaje político español. Datos lexicométricos y notas para una historia conceptual. Revista de Historia Militar, XLIX, 159-219. 
Fernández Sebastián, J. (Dir.) (2014). Diccionario Político y Social del Mundo Iberoamericano. Iberconceptos. Conceptos politicos fundamentales, 1770-1870. Madrid: Universidad del País Vasco, Euskal Erriko Unibersitatea-Centro de Estudios Políticos y Constitucionales.

Flattley, J. (2008). Affective mapping. Melancolia and the politics of modernism. Cambridge Massachussets y Londres: Harvard University Press.

Fradkin, R. (2008). ¿Y el pueblo dónde está? Contribuciones para una historia popular de la revolución de independencia en el Río de la Plata. Buenos Aires: Prometeo.

Frevert, U. (2011). Emotions in History-Lost and Found. Budapest-Nueva York: Central European University Limited Company.

Guerra, F. X. (2003). De la política antigua a la política moderna: algunas proposiciones. Anuario del IEHS, 18, 201-212.

Gil Pujol, X. (2004). Un Rey, una Fe, muchas naciones. Patria y nación en la España de los siglos XVI y XVII. En A. Alvarez-Ossorio Alvariño y B. J. García, La Monarquía de las naciones. Patria, nación y naturaleza en la Monarquía de España (pp. 39-76) Madrid: Fundación Carlos de Amberes.

González Bernaldo de Quirós, P. (1990). Producción de una nueva legitimidad: ejército y sociedades patrióticas en el Buenos Aires entre 1810 y 1813. Cahiers des Amériques Latines, 10, 134-156.

González Bernaldo de Quirós, P. (2001). Civilidad y politica en los orígenes de la nación argentina. Las sociabilidades en Buenos Aires, 1829-1862. Buenos Aires: Fondo de Cultura Económica.

Hall, S. y du Gay, P. (comps) (2003). Cuestiones de identidad cultural. Buenos Aires-Madrid: Amorrortu.

Halperín Donghi, T. (2001). Los orígenes de la nación argentina: un relato que retorna. Entrepasados, 20/21, 143-160.

Hölscher, L. (1996). Los fundamentos teóricos de la historia de los conceptos (Begriffsgeschichte). En I. Olábarri y F. J. Caspistegui (dirs.). La nueva historia cultural: la influencia del postestructuralismo y el auge de la interdisciplinariedad, (pp. 69-82). Madrid: Editorial Complutense.

Imízcoz, J. M. (2017). Actores, procesos de cambio. Reflexiones metodológicas desde el análisis relacional. En T. Nava Rodríguez. De ilustrados a patriotas. Individuo y cambio histórico en la Monarquía española (pp. 19-40). Madrid: Sílex.

Koselleck, R. y Gadamer, H. G. (1997). Historia y hermenéutica. Barcelona: Ed. Paidós.

Lavallé, B. (2010). Patrie(s) et nation(s) dans l'Amérique des Habsbourgs. Nuevo Mundo Mundos Nuevos. Recuperado de http://nuevomundo.revues.org/59291.

Lara, A. y Enciso Domínguez, G. (2013). El Giro Afectivo. Athenea Digital, 13(3), 101-119.

Le Breton, D. (1999). Las pasiones ordinarias. Antropología de las emociones. Buenos Aires: Nueva Visión.

Leys, R. (2011). The turn to affect: a critique. Critical Inquiry, 37, 434-472.

Macon, C. (2013). Sentimus ergo sumus. El surgimiento del "giro afectivo" y su impacto sobre la filosofía política. Revista Latinoamericana de Filosofía política, 2(6), 1-32.

Maggio Ramírez, M. (2016). Civilidad imaginada. La construcción de la civilidad como signo identitario en la prensa tardocolonial porteña. Un análisis del Telégrafo Mercantil, Rural, Económico, Político, Historiográfico del Rio de la Plata y del Semanario de Agricultura, Industria y comercio entre 1801 y 1803. (Tesis doctoral inédita). Universidad de Buenos Aires, Buenos Aires, Argentina.

Martínez Freire, P. (2000). El desafío de las emociones a las ciencias cognitivas. Thémata. Revista de Filosofía, 25, 55-66.

Martínez Peláez, S. (1998). La patria del criollo. Ensayo de interpretación de la realidad colonial guatemalteca. México: Fondo de Cultura Económica.

Matharan, J. L. (2010). Histoire du sentiment d'appartenance en France. Du XXe. Siècle à nos jours. París: L'Harmattan. Matt, S. J. \& Stearns, P. N. (2014). Doing emotions history. Urbana, Chicago, Springfield: University of Illinois Press.

Mazurel, H. (2010). Histoire des sensibilités. En C. Delacroix, C. Dosse, F. P. García y N. Offenstadt. Historiographies, Concepts et débats (pp. 255-261). París: Gallimard. 
Jaime Peire. Emociones y sentimientos Patrióticos (1767-1828): Esbozo para un estudio de los Pat...

Monteagudo, C. (2001). Mundo de la vida en la filosofía de Hans-Georg Gadamer. Areté. Revista de Filosofía, 13(1), 37-57.

Moscoso, J. (2015). La historia de las emociones, ¿̨e qué es historia?. Vinculos de historia, 4, 17-28.

Nebreda, J.J. (2000). El marco de la identidad o las herencias de Parménides. En Las ilusiones de la identidad (pp. 151-180). Madrid: Cátedra.

Nussbaum, M. (2014). Emociones políticas. ¿Por qué el amor es tan importante para la justicia?. Barcelona: Paidós.

Nun, J. (2005). Debates de mayo. Nación, cultura y politica. Buenos Aires: Gedisa.

Nuzzo, E. (2003). Metaforología e historicidad. Sobre algunos problemas y perspectivas de investigación. Quaderns de filosofia i ciència, 32-33, 47-66.

Peire, J. (2008). La "Argentina" de los sentimientos en la lírica rioplatense de ciclo revolucionario: 1767-1825. Anuario IEHS, 23, 17-46.

Peire, J. (2010). Los sentimientos de pertenencia y su evolución en la producción literaria rioplatense entre 1767 y 1825. En M. Terán y V. Gayol. La Corona rota. Identidades y representaciones en las Independencias Iberoamericanas (pp.229-272). Castelló de la Plana: Universitat Jaume I.

Peire, J. (2016). Políticamente incorrectos: sentimientos identitarios en la literatura rural gauchesca. 1770-1828. Anuario del Instituto de Historia Argentina, 16(2), 1-23.

Peire, J. (2018). La política y lo político rioplatense desde 1983 hasta nuestros días: Revolución e independencia. En J. Peire, A. Amadori, y T. Chaile (Eds.). Historiografias politico-culturales rioplatenses. Itinerarios, enfoques y perspectivas recientes sobre el periodo colonial y la independencia (pp. 311-370). Sevilla: Thémata.

Plamper, J. (2014). Historia de las emociones, caminos y retos. Cuadernos de Historia Contemporánea, 36, 17-29

Plamper, J. (2015). The History of emotions, an introduction. Oxford: Oxford University Press.

Puig, J. C. (1910). Antología de Poetas argentinos. Buenos Aires: Martín Biedma e hijos.

Reedy, W. (2009) Historical Research on the Self and Emotions. Emotion Review, 1(4), 302-315.

Rimé, B. (2005). Le partage social des émotions. París: PUF.

Rodríguez García, M. E. (2003). El criollismo limeño y la idea de nación en el Perú tardocolonial. Araucaria, 5(9), 138-162.

Rodríguez Valls, F. (2015). El sujeto emocional. La función de las emociones en la vida humana. Sevilla: Thémata.

Sánchez Capedequí, C. (Coord.) (2003). Cornelius Castoriadis. La pluralidad de los imaginarios de la modernidad. Revista Anthropos. Huellas del conocimiento, 198.

Scheer, M. (2012). Are emotions a kind of practice (And is that what makes them have a history)? A bourdieuian approach to understanding emotion. History and theory, 51, 193-220.

Tío Vallejo, G. y Gayol, V. (2005). Hacia el altar de la patria. Patriotismo y virtudes en la construcción de la conciencia militar y entre las reformas borbónicas y la Revolución de la Independencia. En J. Ortiz Escamilla (Coord.). Fuerzas militares en Iberoamérica. Siglos XVIII y XIX (pp. 111-137). México: El Colegio de México, El Colegio de Michoacán, Universidad Veracruzana.

Tausiet, M. y Amelang, J. S. (2009). Accidentes del alma. Las emociones en la edad moderna. Madrid: Abada editores.

Ternavasio, M. (2007). Gobernar la revolución. Poderes en disputa en el Río de la Plata, 1810-1816. Buenos Aires: Siglo XXI.

Viroli, M. (1997). Por amor a la patria. Un ensayo sobre el patriotismo y el nacionalismo. Madrid: Acento.

Wunenburger, J.J. (2008). Antropología del imaginario. Buenos Aires: Ediciones del Sol.

Zaragoza Bernal, J. M. (2015). Ampliar el marco. Hacia una historia material de las emociones. Vinculos de historia, 4, 28-40. 


\section{Notas}

1 En el caso del Río de la Plata, la circulación de estos enfoques antecedió al surgimiento y auge de la historia de los conceptos, especialmente con la influencia de Reinhart Kosselleck, cuyos estudios comprenden un período que engloba al que estudiamos en este artículo y que se plasmó -entre otros muchos logros- en el valioso Diccionario político y social del Mundo Iberoamericano (Fernández Sebastián, 2009; Brunner, Conze \& Koselleck, 1972-1997; Holschner, 1996; Koselleck y Gadamer, 1997).

2 La patria, considerada desde el punto de vista de las emociones y sentimientos, es algo que ellos construyen de forma procesual; la van sintiendo en el fluir del mundo de la vida. Seguimos en esto a Le Breton (1999): “A la emoción no le hace falta tiempo. La identidad personal no es una sustancia sino un sentimiento y, por lo tanto, no podría darse de otra manera que en la pluralidad de resonancias de la experiencia" (p. 111.), habiendo aclarado que la emoción "es la resonancia propia de un acontecimiento pasado, presente o futuro, real o imaginario, en la relación del individuo con el mundo" (p. 105).

3 Hay dos lecturas fundamentales que dan la pista de las "patrias". Una es teórica y la otra, empírica. Para la primera, Maurizio Viroli (1997), quien además traza una síntesis de las ideas de Patria desde los latinos hasta fines del siglo XIX. La idea principal que se extrae de este trabajo es que patria y nación remiten a representaciones diferentes. En cuanto a la parte más historiográfica, Annino da la pista de que más que una "patria” esencial puede haber "patrias”; cfr. Annino y Rojas (2008). Para la índole de las hibridaciones en los procesos de identificación y en las culturas, cfr. Burke (2010). Otra perspectiva importante del "nosotros" que comporta una patria se puede ver en Matharan (2010) como también en Agulhon (1993), importante para analizar la idea de patria en Francia: algo que será útil retomar en el Río de la Plata revolucionario.

4 Esta cercanía entre el sentimiento y el pensamiento después del Affective turn parece evidente pero no lo era tanto hasta hace unos años. Cfr. Nussbaum (2014, p. 30).

5 "Morir por la patria es dulce" (traducción propia). [El origen de la expresión es: "dulce et decorum est pro- patria mori" proviene de un poema de Horacio: Odas III, 2, 13.]

6 Para ver el problema era la inclusión de los indígenas en esa patria cfr. Elliot (2004, p. 31).

7 En el caso del Río de la Plata merece citarse al santafesino Francisco Javier Iturri. [Aclaro que son válidas ambas grafías, pero se prefiere con " $\mathrm{s}$ ".]

8 María Tausiet y José S. Amelang (2009, p. 8) aclaran: "En los siglos XVI al XVIII se hablaba sobre todo de afectos o pasiones, esto es, de padecimientos pasajeros que afectaban (alteraban) al individuo, para después permitirle volver a su ser”. Es decir , serían "accidentes” contingentes, "a diferencia del alma que, de acuerdo con la definición de Aristóteles, constituía la sustancia -algo necesario y permanente”. Esto habría cambiado -según los mismos autores- con el lenguaje ilustrado. Los autores hacen un racconto de los principales lenguajes acerca de los afectos, emociones y pasiones antes y durante la modernidad.

9 Para un panorama general, véase Lara y Enciso Domínguez (2013), específicamente pp. 108-111, y Ruth Leys (2011, 450). Se utilizará sobre todo a Rodríguez Valls (2015, pp. 85-94) Cfr. Le Breton (1999, pp. 103-125 y 163-176), ya que es un texto sencillo y útil para estos aspectos. El problema de este autor es que parece no distinguir con claridad entre emoción y pasión.

10 Esto puede resultar chocante: pero piénsese, por ejemplo, en el amor de una madre por su hijo o en la ira ante una agresión o la tristeza ante una pérdida: no sería un desatino pensar que las emociones se disparan directamente sin necesidad de ser representadas antes.

11 Cfr. Lara, y Enciso Domínguez, G. (2013, p. 104). Algunos autores enfocan el afecto como algo de mayor o menor intensidad, mientras que otros consideran que, mientras la emoción es del sujeto o viene de "dentro", el afecto viene de "afuera”: el afecto sería más relacional. Flattley, (2008, p. 12) aclara -y es bueno asentarlo- que "emotions" y "affects" son casi sinónimos. Otra semántica podría ser la de Delgado, Fernández y Labanyi (2018).

12 Cfr. Rodríguez Valls $(2015,94)$. Flattley enfatiza esto y define el estado de ánimo o anímico (mood) como "una suerte de atmósfera afectiva en la cual las intenciones son formadas, los proyectos perseguidos y los afectos particulares pueden apegarse a objetos particulares". Se incluirá "estado anímico" en el concepto de "sentimiento" por motivos prácticos (Flattley, 2012, p. 19. La traducción es propia). Flattley se basa en la concepción heideggeriana del dasein (ser o estarahí): siempre se es o se está en algo o en algún lugar o de algún modo; y por supuesto, en algún estado de ánimo. La semántica del dasein subraya que ha sido arrojado allí. Se recogerá aquí esa tradición para imputarla al sentimiento o a las prácticas sentimentales.

13 Rodríguez Valls $(O p$. cit, p. 85). A esto hay que agregar que el significado de los términos, además de ser diferente, no estaba discriminado todavía.

14 “(...) fue en el Romanticismo cuando el término cambió su semántica y debido a motivos internos de su propia forma de filosofar pasó a denominar a una «emoción intensa», un motivo que arrebata en aras, por ejemplo, de la persecución de 
un gran ideal. La pasión acompaña y empuja el espíritu humano fundado en la libertad” (Rodríguez Valls, 2015, p. 86). Este será más bien el sentido en el que será utilizada, aunque había un sentido más genérico que asumía que la pasión era algo irresistible (incluso una ley de la naturaleza) y que para el bando contrario era simplemente irracional o una fantasía peligrosa.

15 Por performance patriótica entendemos el despliegue del sentimiento patriótico, estudiado a partir de la evolución del discurso lírico y dramático (contextualizado con la prensa y otras fuentes) del período analizado diacrónicamente. Esto puede realizarse a partir de la carga semántica del elenco lexical y metafórico -conjunto de términos y metáforas asociadas que expresaban las emociones patrióticas- utilizado en cada uno de los registros lingüísticos.

16 Aunque una patria -y por lo tanto los patriotismos que militan por construirlas- sería algo siempre dinámico, siempre en movimiento si ella no está en proceso de reificación o descomposición.

17 Se ponen a continuación algunos ejemplos que visibilizan este corpus en tramos poco conocidos pues incluir todas las fuentes consultadas sería más largo de lo aconsejable en este artículo. Tengo que aclarar que de cada obra se poseen muy diversas ediciones y que no se harán aquí las advertencias eruditas del caso por una cuestión de pertinencia. Quizás el más importante registro lírico sea La Lira argentina o colección de piezas poéticas dadas a luz en Buenos Aires durante la guerra de su independencia. Después está la recientemente editada Colección de Poesías Patrióticas. También recientemente de E. S. Zeballos (2018) Cancionero popular, Buenos Aires, Poesías Desconocidas de la independencia argentina. Una Antología muy útil es la de Juan C. Puig (1910). Antología de Poetas argentinos. Buenos Aires: Martín Biedma e hijos. T I-IV. Y el Cancionero de las invasiones inglesas (2010). Es de destacar dentro de ese volumen El triunfo argentino, de Vicente López y Planes (1808), que cuenta con muchas ediciones. Para el patriotismo oriental, con su carácter diferente del "argentino", repetidamente señalado, cfr. Acuña de Figueroa, F. (1978). Este Diario está en verso y contiene los primeros Cielitos que se conocen y algunas Seguidillas 'populares' y otras composiciones poéticas. Un trabajo que contiene un análisis parcial de estas obras es Peire (2010). Es útil también consultar El Parnaso Oriental o Guirnalda poética de la República uruguaya (1837). En cuanto a la dramática culta, me remito a las ediciones del Instituto de Literatura Argentina que en los años 20 del siglo XX fueron dirigidas por Ricardo Rojas. Entre ellas, destaco el Siripo de Lavardén por estar poco estudiado, quizás por haberse perdido una parte. Estas obras teatrales podrían ocupar varios volúmenes. Cito a continuación sólo ejemplos de la lírica y la dramática de corte popular. Los Cielitos anteriores a Hidalgo pueden encontrarse en el Diario de Montevideo, Op. cit. T 1, pp. [Supongo que se trata del número de pp. aunque podría tratarse del número de cada composición] 240, 366 y T II, pp. [ídem] 35, 228. Una edición valiosa de las obras de Hidalgo es Hidalgo, B. (1986). En cuanto a la dramática gauchesca, vuelvo a referirme a las ediciones de la década del 20 citadas anteriormente. Son cinco sainetes gauchescos cuyo estudio puede verse en Peire (2016). En cuanto al patriotismo realista, cfr. la correspondencia entre Abascal y Liniers -que está en el Archivo Abascal del Archivo General de Indias (AGI)- y con el mismo Virrey de varias personalidades de Montevideo, que se encuentran tanto en el AGI como en la Biblioteca Nacional de España (BNE). Estas son representativas de un patriotismo realista de antiguo régimen. Más novedoso en su patriotismo es el General Goyeneche en su correspondencia secreta con el Virrey Abascal, que está en el AGI (Diversos). La BNE tiene conservados diarios de Guerra en verso que reflejan dos momentos de patriotismo realista diferentes. Relación exacta de lo que ha sucedido en la expedición a Buenos Ayres que escribe un sargento de la comitiva de ese año de 1778 en las siguientes Décimas, BNE, Ms 10.942, f. 160 vta. y ss. También el largo poema de Quimper, M. Laicas vivacidades de Quimper Antorcha Peruana Acaecimientos del Peru en civiles guerras promovidas por el Reyno de Buenos-Ayres desde el año de 1809 hasta el de 1818. BNE, Ms 3722. Por último, cito en este breve racconto los periódicos del período, cuya lista puede encontrarse en Agostina, H.N. (2000). La mayoría están publicados en la Biblioteca de Mayo. Entre esos periódicos debo resaltar La Gaceta de Montevideo, muy útil a la hora de estudiar el patriotismo realista de Montevideo (1810-1811).

18 Como ya mencioné, esta propuesta metodológica forma parte de un empeño de más largo aliento ya avanzado, del que pueden verse ejemplos en los artículos de mi autoría citados aquí.

19 En realidad, este concepto de "tono" podría relacionarse también con la definición de Flattley de estado de ánimo: estar en un estado de ánimo es estar "en sintonía”; una "sintonización” que es la fundación o el lugar de comienzo para todo, la "presuposición” para nuestro "pensar, hacer o actuar", el medio en el cual esas cosas ocurren. "Uno no está nunca no-sintonizado; uno está siempre en un estado anímico u otro”. Flattley (2008, p. 21). Aunque Flattley no lo enfatiza, "sintonizar" está alineado con el "tono".

20 Zaragoza Bernal "expresa que una estrategia importante en el estudio de las emociones consistirá en la introducción del concepto de espacio como el lugar en que estas relaciones acaecen, y cómo el estudio de estos espacios posibilita la comprensión de las emociones de quienes los habitaron" (2015, p. 37). Sólo que en este caso ese espacio-lugar es mentalcorporal. Sobre los diccionarios, Matías Maggio Ramírez expresa que "escardar los diccionarios para rastrear palabras es útil siempre que se recuerde que la significación no es más que un fragmento del magma histórico, social e imaginario que se sedimenta para placer de los lexicógrafos" (2016, p. 30).

21 Esta idea es una elaboración propia de varias lecturas y trabajos interdisciplinarios, tanto leídos como debatidos: en primer lugar, está tomada de Choza (1983). La idea de la singularidad está tomada de mi labor con la (muy querida) 
Profesora Susana Zanetti, con quien tuve el privilegio de trabajar. Pero el conjunto de la idea de patria como aquí la explico es una semántica personal extraída de las fuentes.

22 "Reflexiones sobre el patriotismo". El Censor, 4 de febrero de 1812.

23 Responsividad en el sentido de Leonor Arfuch (2002, p. 65). Es decir que un autor "presta su voz -aun sin saberlo (...)a otras voces antiguas que expresan sentidos, valores, opiniones, verdades que no necesitan demostración: ese 'zócalo difuso' que podría identificarse como el discurso social".

24 Eustaquio Díaz Vélez a Pío Tristán, AGI, Tucumán, 24 de septiembre de 1812, Diversos 2-2-1-2.

25 La traducción es propia.

\section{BY-NC-SA}

